\title{
Sovereign default risk and commitment for fiscal adjustment
}

Carlos Eduardo Gonçalves BERNARDO GUIMARAES

Working PAPER SERIES № 2012-23 
DEPARTMENT OF ECONOMICS, FEA-USP

WORKING PAPER № 2012-23

\title{
Sovereign default risk and commitment for fiscal adjustment
}

Carlos Eduardo Gonçalves (cesg@usp.br)

Bernardo Guimaraes (bernardo.guimaraes@fgv.br)

\begin{abstract}
:
This paper studies fiscal policy in a model of sovereign debt and default. A time-inconsistency problem arises: since the price of past debt cannot be affected by current fiscal policy and governments cannot credibly commit to a certain path of tax rates, debtor countries choose suboptimally low fiscal adjustments. An international lender of last resort, capable of designing an implicit contract that coax debtors into a tougher fiscal stance via the provision of cheap (but senior) lending in times of crisis, can work as a commitment device and improve social welfare.
\end{abstract}

Keywords: fiscal adjustment, sovereign debt, sovereign default; time inconsistency; IMF.

JEL Codes: F33, F34. 


\title{
Sovereign default risk and commitment for fiscal adjustment*
}

\author{
Carlos Eduardo Gonçalves ${ }^{\dagger} \quad$ Bernardo Guimaraes ${ }^{\ddagger}$
}

September 2012

\begin{abstract}
This paper studies fiscal policy in a model of sovereign debt and default. A time-inconsistency problem arises: since the price of past debt cannot be affected by current fiscal policy and governments cannot credibly commit to a certain path of tax rates, debtor countries choose suboptimally low fiscal adjustments. An international lender of last resort, capable of designing an implicit contract that coax debtors into a tougher fiscal stance via the provision of cheap (but senior) lending in times of crisis, can work as a commitment device and improve social welfare.

KEYWORDS: fiscal adjustment; sovereign debt; sovereign default; time inconsistency; IMF.

Jel Classification: F33; F34.
\end{abstract}

\section{Introduction}

In times of debt crises, a great deal of attention is turned to fiscal adjustment in debtor countries, as the emphasis on fiscal consolidation in Greece, Italy, Ireland and Portugal in the wake of the recent Euro zone crisis vividly exemplifies. This paper analyses fiscal policy in a model of sovereign debt and default along the lines of Eaton and Gersovitz (1981) and Arellano (2008). ${ }^{1}$ Most models in this literature do not separate "country debt" from "government debt", which means they cannot be used to study fiscal adjustment. ${ }^{2}$ A key ingredient of this model is that sovereign debt is paid out of government's available resources, so besides deciding on debt and default, the domestic country also makes choices on fiscal policy. One of the main results is that fiscal policy in debtor countries

\footnotetext{
${ }^{*}$ We thank Tito Cordella, Pedro Teles and seminar participants at the XIV Workshop of International Economics and Finance (UTDT), FGV-Rio and U Sao Paulo for helpful comments.

${ }^{\dagger}$ University of Sao Paulo, Department of Economics. Email: cesg@usp.br

${ }^{\ddagger}$ Sao Paulo School of Economics - FGV. Email: bernardo.guimaraes@fgv.br

${ }^{1}$ There are now many papers building on this framework. Recent references include Aguiar and Gopinath (2006), Alfaro and Kanczuk (2005), Cuadra and Sapriza (2008), Guimaraes (2011), Mendoza and Yue (2012) and Yue (2010).

${ }^{2}$ One important exception is Cuadra, Sanchez and Sapriza (2010). Their model also analyses fiscal policy in a model of sovereign debt and default, but their objective is different. They develop a quantitative model that accounts for procyclicality in fiscal policy in emerging markets. There are also papers studying how that possibility of default (and the actual default) affect tax policy, but differently from here, all the action in those papers come from distortionary taxation (see, e.g., Pouzo, 2010).
} 
suffers from a time inconsistency problem. That has implications for the current policy debate. In particular, we argue that lending of last resort operations coupled with fiscal conditionalities can be interpreted as a commitment device for optimal fiscal adjustment when defaults are costly.

In the model, a tighter fiscal policy reduces the amount of borrowing necessary to repay maturing debt when low output leads to insufficient tax revenues. Lower borrowing needs render it less likely that the debtor country will default in the future, which leads to cheaper borrowing today. These lower odds of default associated with higher taxation are good news since defaults trigger output losses. Since creditors are assumed to be competitive, they break-even in expected terms, so all the benefits from higher tax rates accrue to debtors. One could thus think that the debtor country fiscal choices would be optimal, but that is not true owing to a time inconsistency problem, meaning debtors do not fully internalize the benefits of austerity policies.

Since tax rates can be reset from period to period, whenever the debtor government makes fiscal policy decisions there is a stock of outstanding debt issued in the past. High tax rates diminishes the incidence of future defaults and thus positively influences debt prices, but the problem is that past debt is "sunk" and hence its price is not impacted by current fiscal decisions - prices react in secondary markets, but that bears no benefit to the government's budget (in terms of the amount disembursed to repay past debt). Therefore, compared to the social optimum, there is too little fiscal adjustment and too much default in equilibrium. Since rational creditors break-even, the lack of fiscal adjustment and excessive default incidence only harms the debtor itself. This means the debtor would like to pledge higher future taxes; only it cannot do it credibly, since ex-post its incentives for fiscal adjustment are weakened, a fact anticipated by creditors.

In theory, one can easily devise private contracts to address this time-inconsistency problem. For example, the debtor country could issue bonds with a clause stating that at certain states of nature the bond holder would transfer to the debtor country some extra money upon observing tough fiscal policies. This would provide the necessary incentives for fiscal adjustment ex post. Trouble is, this contract in practice wouldn't be workable. The bond holder and debtor would have to know and agree that a certain state of nature had materialized, and the creditor would have to determine if the proper level of fiscal adjustment was accordingly implemented. The problem is that individual bond holders would like to free ride on the verifying efforts of others. Thus, most likely transaction costs end up preventing a Coase-theorem type of solution to this problem.

However, a benevolent international lender of last resort, with seniority, can mimic 
this contract. An international lender of last resort like the IMF faces no free-riding problem and would arguably have the proper incentives to pay the costs to observe states of nature and evaluate the implementation of fiscal policy decisions. It could then lend money to debtor countries at subsidized rates upon observing tough fiscal policies (which is reminiscent of the conditionalities imposed by the IMF on debtors). The carrot of financial aid in times of crisis would provide debtors with the appropriate incentives for fiscal adjustment. Owing to the IMF's seniority status, the creditors who become junior lenders when the IMF gets involved are the ones who would really be footing the bill of IMF's subsidized lending. The model also implies that the cheapest way - in terms of resources needed to satisfy the debtor's participation constraint - to implement this deal is for the IMF to transfer money to the debtor country (or lend at subsidized rates) when the debtor would use those resources to repay maturing debt - i.e., in times of crises. These are the times when an IMF's dollar is worth more because relaxing the debtor's budget constraint has a positive impact on the price of debt. This sort of implicit contract arrangement is consistent with the observation of tough fiscal policies being implemented in debtor countries that then receive subsidized lending from international institutions in times of high default risk.

Lending of last resort operations are usually conditional on the implementation of tougher fiscal policies. International lenders of last resort acting to salvage countries from financial meltdowns usually specify fiscal goals for recipients in exchange for financial aid. This paper views IMF fiscal conditionalities in lending programs as a device to help debtors circumvent a time-inconsistency problem in fiscal policy that they find difficult to tackle by themselves. This is different from the many possible rationales for IMF conditionality found in the literature. Dreher (2009) presents a comprehensive survey of this literature and discusses the proposed explanations for IMF conditionalities. ${ }^{3}$ Some of them are related to commitment problems, but not to time-inconsistency in fiscal adjustment. Fafchamps (2007), for example, shows trade reforms can increase the costs of default and hence increase incentives to repay debt, so conditionalities on trade reform would help to ameliorate the problem of commitment to repay debt. Sachs (1989), in turn, focuses on a moral hazard problem according to which a country has incentives to consume its borrowing proceeds instead of investing (once lending is done), which increases incentives for debt repudiation in the future. In this setting, earmarking the funds to investment (a type of conditionality) would help the country to circumvent the problem.

\footnotetext{
${ }^{3}$ See also the survey in Bird (2007) about the IMF.
} 
One implication of our model is that it is wrong to evaluate the desirability of IMF programs based solely on a comparison between the time-consistent fiscal policy and the one imposed by the IMF, not only because conditionalities come attached with financial support, but because the time-consistent fiscal policy is itself suboptimal. Another implication is that shocks that negatively affect IMF's lending capacity might push debtors away from a tight fiscal policy, which is the opposite of the usual moral hazard critique associated with IMF lending.

The paper is organized as follows. Section 2 describes the model, Section 3 derives the results, Section 4 discusses IMF lending and some developments in the Euro zone debt crisis under the light of the model and Section 5 concludes.

\section{The model}

\subsection{Environment}

Consider a stochastic endowment economy governed by a benevolent sovereign able to access international capital markets and levy domestic taxes. The government maximizes its citizens' utility, assigns no weight to foreign creditors' welfare and cannot commit to repay its maturing debt. In each period, upon observing the realization of the stochastic endowment, $y$, it chooses between repaying maturing debt or defaulting.

After debt and default decisions have been made, at the last stage of any given period the tax rate $\tau^{\prime}$ prevailing in the following period is chosen. It is assumed that taxes can't be altered within a certain period and after the government observes $y$. The tax rate $\tau$ cannot be made contingent on $y$ either.

The representative consumer in the debtor country has utility:

$$
U=u(c)+g
$$

where $c$ is consumption and equals disposable income, $u($.$) is a strictly increasing and$ strictly concave function, $g$ is government spending. Both $c$ and $g$ have to be non-negative. The debtor country's representative agent receives a stochastic endowment $y$ drawn from a probability density function $f$, which is continuous with full support in the $\left[y_{L}, y_{H}\right]$ interval, with $y_{H}>y_{L}>0$. For simplicity, we assume that the variables $y$ are independently distributed over time. It is also assumed that $u^{\prime}(0) \rightarrow \infty$ and $u^{\prime}\left(y_{L}\right)<1$. The former means that a country will never allocate all its resources to the provision of public goods and the latter ensures that in a country with no debt, even with the lowest possible realization of $y$, the optimal $g$ is greater than zero. 
As usual in this literature, default leads to output losses. Output net of default costs is denoted by $\hat{y}$; if there is no default $\hat{y}=y$. If the country chooses to default in period $t$, output falls to $\hat{y}^{\prime}=(1-\gamma) y^{\prime}$ from $t+1$ on, where $\gamma>0$. Moreover, upon defaulting the debtor is banished from capital markets. In the subsequent periods, the punishment ceases with an exogenous probability $\zeta$. When the debtor reenters capital markets, it does so with an outstanding debt equal to $\nu d^{\prime}$, where $\nu$ is a positive constant. ${ }^{4}$

The private sector has no access to external capital markets and hence private consumption equals net income:

$$
c=\hat{y}(1-\tau)
$$

The government raises debt with the following maturity structure: every period a fraction $\phi$ of the outstanding debt stock comes due and $1-\phi$ goes on to add to the next period's debt pile. This is equivalent to assuming that the government every period issues debt with varying maturities, being $\phi$ the proportion of debt coming due in $t+1$ as a fraction of debt maturing in $t$. We assume $0<\nu<\phi<1$.

If the government starts period $t$ with some inherited debt $d, \phi d$ is the amount that has to be repaid in $t$. If it opts to issue new debt $b$ at an endogenous price $q$, the total stock of debt one period ahead will be given by $d^{\prime}=(1-\phi) d+b$. Government spending is thus given by:

$$
\begin{aligned}
& g=\tau y \quad \text { in case of default } \\
& g=\tau y-\phi d+q b \quad \text { otherwise }
\end{aligned}
$$

subject to $g \geq 0$. We will loosely refer to the condition $\tau y-\phi d+q b \geq 0$ as the "government budget constraint".

As usual, there is a maximum level of debt that prevents the country from running a Ponzi scheme but is not binding otherwise.

Creditors are risk neutral and $1+r^{*}$ is the gross risk-free interest rate. There is perfect competitions among foreign lenders so creditors always break even in terms of expected returns. The time-discount factor is $\beta$. We assume $\beta\left(1+r^{*}\right)<1$, so that the country has incentives to borrow at the point of zero probability of default.

Define $\pi_{1}$ the probability debt $\phi d^{\prime}$ is repaid in the following period. Also define $q\left(d^{\prime}\right)$ as the price of this debt by the time it is issued, and $q\left(d^{\prime \prime}\right)$ its price prevailing in the subsequent period if default did not occur. In case of no default, the value of one unit of

\footnotetext{
${ }^{4}$ As documented by Sturzenegger and Zettelmeyer (2008), creditors usually recover a sizable part of their lending following default episodes.
} 
debt in the following period is

$$
\frac{\phi+(1-\phi) E\left[q\left(d^{\prime \prime}\right)\right]}{\left(1+r^{*}\right)}
$$

If default does occur (which happens with probability $1-\pi_{1}$ ), the debtor is banned from capital markets for one period and then regain access in the following periods with a per period probability equal to $\zeta$. The value of one unit of debt at the second period if the country had defaulted in the first is equal to:

$$
\frac{\nu q\left(\nu d^{\prime}\right)}{\left(1+r^{*}\right)}\left(\frac{\zeta}{\left(1+r^{*}\right)}+\frac{(1-\zeta) \zeta}{\left(1+r^{*}\right)^{2}}+\ldots\right)=\frac{\nu q\left(\nu d^{\prime}\right)}{\left(1+r^{*}\right)} \frac{\zeta}{\left(\zeta+r^{*}\right)}
$$

Putting both parts together: ${ }^{5}$

$$
q\left(d^{\prime}\right)=\pi_{1}\left[\frac{\phi+(1-\phi) E q\left(d^{\prime \prime}\right)}{\left(1+r^{*}\right)}\right]+\left(1-\pi_{1}\right)\left[\frac{\nu q\left(\nu d^{\prime}\right)}{\left(1+r^{*}\right)} \frac{\zeta}{\left(\zeta+r^{*}\right)}\right]
$$

Note that this expression assumes there are no varying degrees of seniority, so the debtor owes $\nu$ for every previously contracted unit of debt when it regains access to financial markets. Seniority would affect the second term, the value of the bond in case of default.

The sequence of events in a given discrete time period is the following:

1. $y$ is revealed;

2. decisions about defaulting on maturing debt $\phi d$ and floating new debt obligations $b$ are made;

3. the tax rate prevailing next period $\tau^{\prime}$ is chosen.

Debt and default decisions are made after $y$ is observed but before $\tau^{\prime}$ has been chosen, reflecting the idea that the country cannot commit to a certain level of taxes when it issues debt.

The value function associated with repaying debt is:

$$
V_{p}(\tau, d, y)=\max _{b}\left\{u([1-\tau] y)+\tau y-\phi d+q b+\beta E V\left(\tau^{\prime}((1-\phi) d+b),(1-\phi) d+b, y^{\prime}\right)\right\}
$$

where $\tau^{\prime}\left(d^{\prime}\right)$ maximizes

$$
u([1-\tau] y)+\tau y-\phi d+q b+\beta E V\left(\tau^{\prime}\left(d^{\prime}\right), d^{\prime}, y^{\prime}\right)
$$

\footnotetext{
${ }^{5}$ In a non-default scenario, the price $q$ of a bond with the maturity structure given above is:$$
q^{*}=\frac{\phi}{\left(1+r^{*}\right)}+\frac{(1-\phi) \phi}{\left(1+r^{*}\right)^{2}}+\ldots+\frac{(1-\phi)^{i-2} \phi}{\left(1+r^{*}\right)^{i-1}}+\ldots=\frac{\phi}{\left(\phi+r^{*}\right)}
$$$$
\text { Substituting } \pi_{1}=1 \text { and } q^{*}=q\left(d^{\prime}\right)=q\left(d^{\prime \prime}\right) \text { into equation (1) yields } q^{*}=\phi /\left(\phi+r^{*}\right) \text {. }
$$ 
taking $d^{\prime}=(1-\phi) d+b$ as given. $V$ is the maximum of two value functions:

$$
V\left(\tau^{\prime}, d^{\prime}, y^{\prime}\right)=\max \left\{V_{p}\left(\tau^{\prime}, d^{\prime}, y^{\prime}\right), V_{d}\left(\tau^{\prime}, d^{\prime}, y^{\prime}\right)\right\}
$$

If the government opts to default, the value function is:

$$
V_{d}(\tau, d, y)=\max _{\tau^{\prime}}\left\{u([1-\tau] y)+\tau y+\beta E V_{0}\left(\tau^{\prime}, d, y^{\prime}\right)\right\}
$$

where

$$
V_{0}\left(\tau^{\prime}, y^{\prime}, d\right)=\max _{\tau^{\prime \prime}}\left\{u\left(\left[1-\tau^{\prime}\right] \hat{y}^{\prime}\right)+\tau^{\prime} \hat{y}^{\prime}+\beta\left[(1-\zeta) E V_{0}\left(\tau^{\prime \prime}, y^{\prime \prime}, d\right)+\zeta E V\left(\tau^{\prime \prime}, \nu d, y^{\prime \prime}\right)\right]\right\}
$$

and $\hat{y}^{\prime}=(1-\gamma) y^{\prime}$. The default punishment kicks in one period after the default decision. As a tie-breaking convention, we will suppose that the country repays debt if indifferent.

\subsection{Discussion of assumptions}

A crucial assumption of the model is that debt and default decisions are made before the tax rate is chosen. That corresponds to a world where a sizable part of debt has already been contracted when fiscal policy decisions that affect debt repayment are made. It is also assumed that debt contracts cannot be made contingent neither on tax policy nor on output, as in most instances in the real world.

We also assume that the tax rate $\tau$ cannot be modified after $y$ is revealed. This captures a well-known feature of tax regimes: they generally require some time to be altered. While real world governments do reset tax rates, significant lags often exist between a perceived need to collect more revenues and cash flowing into public coffers. Immediately changing taxation on private wealth would be akin to sheer expropriation. We incorporate this widely accepted feature as an assumption in our model. The important implication of this assumption is that fluctuations in $y$ affect tax revenues available for debt payment, which is also observed in reality.

The modell features an endowment economy, so taxes are not distortionary. While distortionary taxation could add some twists to the results, it should not affect the main insights of the paper.

In many quantitative papers in the sovereign debt literature, default cost depends positively on $y$, the current realization of output. This feature nearly automatically generates default in bad times. By assuming (i) that output losses due to the default occur only one period ahead and (ii) that $y^{\prime}$ is unrelated to $y$, we are shutting down this channel here. Similarly, a utility function concave in $g$ could induce default in bad times due to higher marginal benefits of public expenditures when these are low (because a low 
$y$ means low tax revenues for a given tax rate $\tau$ ). Linearity in $g$ thus means this channel too is not at work in our model. Together these two assumptions make it easier to isolate the default channel stressed in this paper, the "government budget constraint channel", and they also allow us to obtain analytical results.

The assumption of $\beta\left(1+r^{*}\right)<1$ gives a reason for the domestic country to borrow. It is a usual assumption in the literature and can be thought as a reduced form for other motivations for sovereign debt (say investment in public infrastructure). Linearity in $g$ implies the government would like to have all government spending as early as possible (this results is presented in Appendix A.1).

There is no consensus in the literature about the underlying sources of default costs. The usually mentioned channels include: losses from declining trade ${ }^{6}{ }^{\text {increases in in- }}$ ternational borrowing costs or exclusion from financial markets; ${ }^{7}$ other costs related to reputational loss $;^{8}$ unplanned redistribution of income $;{ }^{9}$ and liquidity problems that lead to reduction in domestic investment. ${ }^{10}$ Regardless of the sources of default penalties, what is important for our purposes is that not repaying in full entails costs to the debtor, and these costs are deadweight losses.

In order to have a role for seniority, a few features usually absent from dynamic models of sovereign debt were added. We assume that part of the debt is recovered, which makes the problem a bit more convoluted than with the usual assumption of no repayment in case of default. Without this assumption, being a senior creditor makes no difference: either all creditors are fully repaid or all creditors receive nothing. Moreover, the simpler one-period debt assumption also needed to be shed. When debt contracted in past periods comes due smoothly in future periods, IMF seniority affects the price of previously issued debt. Our maturity structure allows for all these effects of seniority but keeps the problem dynamically recursive. ${ }^{11}$

\subsection{Benchmark case: uncontingent taxes and no debt}

Here we describe a benchmark case in which the country has no access to capital markets, so there are no default concerns. A benevolent government chooses $\tau^{\prime}$ in order to maximize

\footnotetext{
${ }^{6}$ Empirical evidence includes Rose (2005) and Martinez and Sandleris (2011).

${ }^{7}$ Exclusion from international capital markets is a usual assumption in models following Eaton and Gersovitz (1981). Empirical evidence can be found in English (1995) and Fuentes and Saravia (2010).

${ }^{8}$ Tomz (2007) argues that reputational concerns are important for default decisions.

${ }^{9}$ See, e.g., Broner and Ventura (2011).

${ }^{10}$ See Brutti (2011) for a model. The survey in Panizza, Sturzenegger and Zettelmeyer (2009) highlights the importance of these domestic costs.

${ }^{11}$ Another consequence of our maturity structure is that new debt makes old debt less valuable as in Hatchondo, Martizez and Sosa-Padilla (2012), but this problem is not the focus of this paper.
} 
(3) with $b=d=d^{\prime}=0$. The tax rate $\tau^{\prime}$ only affects the term $E V\left(\tau^{\prime}, 0, y^{\prime}\right)$ and since there is never default that can be written as:

$$
\int_{y_{L}}^{y_{H}}\left\{u\left([1-\tau] y^{\prime}\right)+\tau y^{\prime}+\beta E V_{p}\left(\tau^{\prime \prime}, 0, y^{\prime \prime}\right)\right\} f\left(y^{\prime}\right) d y
$$

The first order condition of this simple problem is:

$$
\int_{y_{L}}^{y_{H}}\left\{y^{\prime}\left[1-u^{\prime}\left((1-\tau) y^{\prime}\right)\right]\right\} f\left(y^{\prime}\right) d y=0
$$

Essentially, the expression above equates the expected marginal benefit of an additional unit of the public good to its marginal cost in terms of reduced private consumption. Under our assumptions the benchmark $\tau$ is larger than 0 and smaller than 1 . If $\tau=1$, $c=0$, so the marginal utility of consumption goes to $-\infty$. On the other hand if $\tau=0$, $c=y \geq y_{L}, u^{\prime}(c) \leq u^{\prime}\left(y_{L}\right)<1$, and hence the integral would be strictly positive.

\section{Equilibrium}

\subsection{Choice of debt and default}

Default decisions are made following the realization of output $y$. If the country chooses to repay its debt, it also chooses debt (or assets) to be carried to the next period. Given inherited debt $d$, total liabilities carried over to the next period are $d^{\prime}=(1-\phi) d+b$, with $q b$ being the amount of resources currently raised.

We start by showing that whether or not the government budget binds is crucial for our results.

Proposition 1 When the constraint $g \geq 0$ is slack, the derivatives of the value functions with respect to $y$ are

$$
\frac{d V_{p}}{d y}=\frac{d V_{d}}{d y}=u^{\prime}(y(1-\tau))(1-\tau)+\tau
$$

Hence lifting the constraint $g \geq 0$, there is never default.

Proof. See appendix.

As long as $g>0$, shocks to $y$ affect $V_{p}$ and $V_{d}$ in exactly the same way: lower $y$ diminishes private and public consumption to the same extent ( $\tau$ is predetermined). But this is so only as long as variations in $y$ have no bearing on the choice of $q b$, which matters for $V_{p}$ but not for $V_{d}{ }^{12}$

\footnotetext{
${ }^{12}$ The i.i.d assumption is important here: if $y$ and $y^{\prime}$ were linked, output shocks would also affect current value functions through their impact on the expected value of future value functions.
} 
If the difference between $V_{p}$ and $V_{d}$ is not subject to shocks, then default is either a zero-probability event or a certain event. The latter is ruled out because it implies $q=0$ and it is never optimal for the debtor to sell debt ta zero price (the debtor would be better off by borrowing nothing and avoiding default punishment).

Since $\tau, y$ and $d$ are predetermined, only $q b$ can affect the constraint $\tau y-\phi d+q b \geq 0$. Differentiating $q b$ with respect to $b$ yields

$$
\frac{\partial(q b)}{\partial b}=q(1-\epsilon) \quad \text { where } \quad \epsilon=-\frac{\partial q}{\partial b} \frac{b}{q}
$$

Lemma 5 (in the appendix) implies that the probability of repayment is (weakly) decreasing in the level of debt. Hence extra debt $\Delta b$ will tend to increase the inflow of resources by less than $q \Delta b$ because the increase in $b$ adversely affects the price of debt $q$. The size of this effect on the price of debt is given by the elasticity parameter $\epsilon$.

The following proposition states when default can occur.

Proposition 2 Default occurs when tax revenues are low:

1. Default can only happen in bad times: for given $\tau$ and $d$, if there is default for some $y \in\left[y_{L}, y_{H}\right]$ then there is default if and only if $y<\tilde{y}$ for some $\tilde{y} \in\left[y_{L}, y_{H}\right]$.

2. Default is more likely when $\tau$ is smaller: for given $y$ and $d$, if there is default for some $\tau \in\left[\tau_{L}, \tau_{H}\right]$ then there is default if and only if $\tau<\tilde{\tau}$ for some $\tilde{\tau} \in\left[\tau_{L}, \tau_{H}\right]$.

3. If the probability of default next period is positive, than it is strictly decreasing in $\tau^{\prime}$.

Proof. See appendix.

A country that repays maturing debt also chooses new debt, $b$. Since default occurs for $y<\tilde{y}$, the value function in (2) becomes:

$$
V_{p}(\tau, d, y)=\max _{b}\left\{\begin{array}{c}
u(y(1-\tau))+\tau y-\phi d+q b+ \\
\beta\left[\int_{y_{L}}^{\tilde{y}} V_{d}\left(\tau^{\prime}, y^{\prime}\right) f(y) d y+\int_{\tilde{y}}^{y_{H}} V_{p}\left(\tau^{\prime}\left(d^{\prime}\right),(1-\phi) d+b, y^{\prime}\right) f(y) d y\right]
\end{array}\right\}
$$

The choice of $b$ depends on whether the government budget constraint binds. If it does not bind, then $\tau y-\phi d+q b>0$ and we obtain the following first order condition: ${ }^{13}$

$$
q(1-\epsilon)+\beta \int_{\tilde{y}}^{y_{H}} \frac{\partial V_{p}\left(\tau^{\prime},(1-\phi) d+b_{u}, y^{\prime}\right)}{\partial b} f(y) d y=0
$$

\footnotetext{
${ }^{13}$ Since $\tau^{\prime}$ is a function of $d^{\prime}=(1-\phi) d+b$, a chance in $b$ could also affect the value function through its effect on the choice of $\tau^{\prime}$. Indeed, the derivative of $V_{p}$ with respect to $b$ includes the term $\frac{\partial E V\left(\tau^{\prime}, d^{\prime}, y^{\prime}\right)}{\partial \tau^{\prime}} \frac{\partial \tau^{\prime}}{\partial b}$ but since $\tau^{\prime}$ will be optimally chosen, the first derivative term is zero.
} 
where $b_{u}$ is the level of borrowing chosen if the constraint $g \geq 0$ is not binding. In the case where the constraint binds,

$$
b_{\min }=\frac{\phi d-\tau y}{q}
$$

A lower $\tau y$ implies a larger minimum level of borrowing $b_{\min }$ in case the country pays its maturing debt.

The intuition for the first statement of Proposition 2 is the following: in bad states of nature (low $y$ ) the government constraint binds with $g=0$, which leads to a larger reduction in $V_{p}$ in comparison to $V_{d}$. The optimal unconstrained borrowing $b_{u}$ is not feasible anymore when output turns out too low and the government chooses to repay. Additional resources need to be raised in capital markets to make up for the shortfall in revenues if the country decides to honor its debt. The constrained level of borrowing $b_{\min }>b_{u}$ will then be suboptimally large in case of repayment. Intuitively, higher financing needs $(\phi d-\tau y)$ translates into a greater probability that the debtor will be unable to honor the debt floated today when it comes due in the future, which drives the price of debt today down (or, analogously, drives up interest rates). That does not imply that the debtor will be transferring more money to creditors (as may sound intuitive at first blush) because creditors always break-even in expected terms: higher interest rates are completely offset by the higher risk of default. But a larger amount of debt increases the probability of a future default, which is costly. Hence higher debt renders the option of repaying relatively more costly.

Empirical evidence suggests countries tend to default in bad times (Tomz and Wright, 2007). However, that real world feature is not easy to obtain in dynamic models of sovereign debt. Guimaraes (2011) shows that punishing costs proportional to output don't generate enough incentives for default in low output states. Arellano (2008) and Cuadra, Sanchez and Sapriza (2010) models deliver default in bad times but with a stronger assumption: they assume default costs are large at booms but zero in recessions, which mechanically generates incentives for default in bad times. ${ }^{14}$

Here, a significant shortfall in revenues increases the amount of debt needed to avoid an immediate default, but larger debt issues increase interest rates and the probability of default in the future. From an accounting perspective, the increase in interest rates and the decrease in the probability of repayment cancel each other. However, from an economic perspective, the decrease in the probability of repaying increases the probability

\footnotetext{
${ }^{14}$ Mendoza and Yue (2012) provide an alternative explanation for default in bad times based on the need to raise working capital through loans to pay for imported inputs.
} 
of facing output costs in the future. Hence an increase in financing needs effectively render the decision to borrow funds economically more costly.

The intuition for the second statement is essentially the same. Tax revenues are given by $\tau y$, so low realizations of $y$ and low values of $\tau$ play a similar role in the choice of debt and default. For the third statement, note that higher tax rates imply a lower threshold $\tilde{y}$ for default (the set of values for $y$ that leads to default is smaller), and since the distribution of $y$ has full support, a larger $\tau^{\prime}$ leads to a smaller probability of default.

\subsection{The choice of fiscal policy}

We focus on the case the debtor has not defaulted in the current period, so there might be risk of default in the following period. The optimal tax rate $\tau^{\prime}$ in equilibrium comes from maximizing (3) taking the level of debt for the following period $d^{\prime}$ as given (owing to the assumptions on timing). The first order condition for $\tau^{\prime}$ is simply:

$$
\frac{\partial E V\left(\tau^{\prime}, d^{\prime}, y^{\prime}\right)}{\partial \tau^{\prime}}=0
$$

Now what if the government could commit to some $\tau^{\prime}$ when it issues debt $b$ ? The value function is case of default is unchanged as in (4), but the value function in case of repayment becomes

$$
V_{p}(\tau, d, y)=\max _{\tau^{\prime}, b}\left\{u([1-\tau] y)+\tau y-\phi d+q b+\beta E V\left(\tau^{\prime},(1-\phi) d+b, y^{\prime}\right)\right\}
$$

and $q$ is now a function of both $d^{\prime}$ and $\tau^{\prime}$. The expression for $q$ is still given by (1) but now changes in $\tau^{\prime}$ affect the price of debt through the probability of default and the price of debt in the following period $\left(\pi_{1}\right.$ and $\left.q\left(d^{\prime \prime}\right)\right)$. Then next proposition establishes that $\tau^{\prime}$ positively affects the price of debt.

Proposition 3 If the probability of default next period is positive and the debtor can commit to a value of $\tau^{\prime}$ when issuing debt:

$$
\frac{\partial q}{\partial \tau^{\prime}}>0
$$

Proof. See appendix.

An increase in $\tau^{\prime}$ increases the probability of repayment for the reasons discussed in Proposition 2, and that is reflected in $q$. Higher taxation means less refinancing needs and thus smaller chances of defaulting in the future. This is fully priced into interest rates given the assumption of perfectly competitive capital markets. 
We now show that if the debtor could commit to a certain level of taxes, the chosen $\tau^{\prime}$ would be larger. In this case, $\tau^{\prime}$ maximizes the expression for $V_{p}(\tau, d, y)$ in $(8)$, taking into account the effect of $\tau^{\prime}$ on $q$. The solution to the maximization problem for $\tau^{\prime}$ depends on whether the constraint $g \geq 0$ binds. Suppose first it does not bind. Then $\tau y-\phi d+q b>0$ and

$$
\frac{\partial V_{p}(\tau, d, y)}{\partial \tau^{\prime}}=\frac{\partial(q b)}{\partial \tau^{\prime}}+\beta \int_{\tilde{y}}^{y_{H}} \frac{\partial V_{p}\left(\tau^{\prime},(1-\phi) d+b, y^{\prime}\right)}{\partial b} \frac{\partial b}{\partial \tau^{\prime}} f(y) d y+\beta \frac{\partial E V\left(\tau^{\prime}, d^{\prime}, y^{\prime}\right)}{\partial \tau^{\prime}}
$$

now

$$
\begin{aligned}
\frac{\partial(q b)}{\partial \tau^{\prime}} & =\frac{\partial(q b)}{\partial \tau^{\prime}}+\frac{\partial(q b)}{\partial b} \frac{\partial b}{\partial \tau^{\prime}} \\
& =b \frac{\partial q}{\partial \tau^{\prime}}+q(1-\epsilon) \frac{\partial b}{\partial \tau^{\prime}}
\end{aligned}
$$

so we get:

$\frac{\partial V_{p}(\tau, d, y)}{\partial \tau^{\prime}}=b \frac{\partial q}{\partial \tau^{\prime}}+\frac{\partial b}{\partial \tau^{\prime}}\left(q(1-\epsilon)+\beta \int_{\tilde{y}}^{y_{H}} \frac{\partial V_{p}\left(\tau^{\prime},(1-\phi) d+b, y^{\prime}\right)}{\partial b} f\left(y^{\prime}\right) d y^{\prime}\right)+\beta \frac{\partial E V\left(\tau^{\prime}, d^{\prime}, y^{\prime}\right)}{\partial \tau^{\prime}}$

The optimal level of borrowing is given by the expression in (6). Substituting that in the above expression yields:

$$
\frac{\partial V_{p}(\tau, d, y)}{\partial \tau^{\prime}}=b \frac{\partial q}{\partial \tau^{\prime}}+\frac{\partial E V\left(\tau^{\prime}, d^{\prime}\right)}{\partial \tau^{\prime}}
$$

Now suppose the constraint $g \geq 0$ binds so that $\tau y-\phi d+q b=0$. Taking the derivative of $b$ from (7) with respect to $\tau^{\prime}$ yields

$$
\frac{\partial b}{\partial \tau^{\prime}}=-\frac{(\phi d-\tau y)}{q^{2}} \frac{\partial q}{\partial \tau^{\prime}}
$$

which implies

$$
\begin{aligned}
\frac{\partial V_{p}(\tau, d, y)}{\partial \tau^{\prime}} & =\beta\left(\int_{\tilde{y}}^{y_{H}} \frac{\partial V_{p}\left(\tau^{\prime},(1-\phi) d+b, y^{\prime}\right)}{\partial b} \frac{\partial b}{\partial \tau^{\prime}} f\left(y^{\prime}\right) d y^{\prime}+\frac{\partial E V\left(\tau^{\prime}, d^{\prime}, y^{\prime}\right)}{\partial \tau^{\prime}}\right)=\quad(10) \\
& =\beta\left(-\frac{(\phi d-\tau y)}{q^{2}} \frac{\partial q}{\partial \tau^{\prime}} \int_{\tilde{y}}^{y_{H}} \frac{\partial V_{p}\left(\tau^{\prime},(1-\phi) d+b, y^{\prime}\right)}{\partial b} f\left(y^{\prime}\right) d y^{\prime}+\frac{\partial E V\left(\tau^{\prime}, d^{\prime}, y^{\prime}\right)}{\partial \tau^{\prime}}\right)
\end{aligned}
$$

The main result of this section is summarized in the next proposition.

Proposition 4 If a country under default risk can commit to a value of $\tau^{\prime}$ when issuing debt, the chosen level of $\tau^{\prime}$ is larger.

Proof. The proof is done by contradiction.

First consider the uncontrained case, given by (9). Suppose that $\tau^{\prime}$ is equal to the case without commitment. In this case $b$ is the same since it is given by the same equation. 
Using Proposition 3 and as $b>0$ by assumption, $\partial V_{p} / \partial \tau^{\prime}>0$, which is a contradiction. If $\tau^{\prime}$ is smaller than in the case without commitment, then the second term in (9) is positive and as the first term is also positive, $\partial V_{p} / \partial \tau^{\prime}>0$, which is a contradiction.

Now consider the constrained case given by (10). The first term of the derivative is positive (the derivative inside the integral is negative and all other terms are positive with a negative sign). Again, if $\tau^{\prime}$ is chosen to be equal or smaller than the case without commitment, $\partial V_{p} / \partial \tau^{\prime}>0$ at the optimal $\tau^{\prime}$, which is a contradiction.

Intuitively, if commitment is feasible, a pledge to implement a certain $\tau^{\prime}$ will be fully incorporated in bond prices, which increases the incentives for additional fiscal adjustment. The inability to commit to a future level of taxes coupled with the timing structure (the tax rate is chosen when debt has already been contracted) is what renders the equilibrium tax rate suboptimal.

It is the debtor itself that benefits from higher taxes since these mean less frequent defaults, which are costly events. Debtors do internalize the fact that higher taxes lead to less frequent defaults when deciding how much to tax the private sector endowment. The problem, however, is that as a consequence of time inconsistency, this internalization is incomplete. A pledge of high future tax rates is judged not credible because ex-post, with the price of debt already set, debtors' incentives are altered: they do not reap additional benefits in terms of lower interest rates by sticking to any promised higher tax rate. If debtors could somehow commit to higher taxes, they would fully benefit from the effects of these on interest rates. The time-inconsistency problem is then unfortunate to them, leading to smaller welfare via suboptimally frequent default events.

\subsection{A private contract with lenders}

Denote the optimal tax adjustment by $\tau^{*}$ and the equilibrium (time-consistent) fiscal adjustment by $\tau_{e q}$. A contingent debt contract that provides incentives for the debtor to choose a less preferred fiscal stance ex-post can lead to $\tau>\tau_{e q}$.

Consider a debt contract such that the value to be repaid is:

$$
\begin{aligned}
& b_{L} \quad \text { if } \tau^{\prime}=\tau^{*} \\
& b_{H} \quad \text { if } \tau^{\prime}<\tau^{*}
\end{aligned}
$$

with $b_{L}<b_{H}$. Repaying $b_{H}$ amounts to an interest rate punishment for not having fulfilled $\tau^{*}$. With this contract, in equilibrium the debtor would have the incentives to implement $\tau^{*}$ in the next period if: 


$$
E_{y}\left(\max \left\{V_{p}\left(\tau^{*}, d_{L}, y\right), V_{d}\left(\tau^{*}, y\right)\right\}-\max \left\{V_{p}\left(\tau_{e q}, d_{H}, y\right), V_{d}\left(\tau_{e q}, y\right)\right\}\right)>0
$$

with $d_{L}=(1-\phi) d+b_{L}$ and $d_{H}=(1-\phi) d+b_{H}$.

In equilibrium, if this inequality holds, the optimal tax rate $\tau^{*}$ is indeed implemented and repayment is always $b_{L}$. Debt will be priced under the assumption $\tau^{\prime}=\tau^{*}$, there will be less default, and thus the debtor will be better off.

For a small $\Delta \tau=\tau^{*}-\tau_{e q}$, the required compensation is of second-order magnitude. Since the tax rate is optimally chosen, that comes from a simple application of the envelope theorem. So there is always room for implementing a larger $\tau^{\prime}$. But there is a limit to how much a contract can affect debtor's incentives because if the punishment is too harsh, the debtor might prefer to default and implement $\tau_{e q}$ instead. An upper bound to the amount of incentives that can be given to the debtor comes from setting such a large $b_{H}$ that $\max \left\{V_{p}\left(\tau_{e q}, d_{H}, y\right), V_{d}\left(\tau_{e q}, y\right)\right\}=V_{d}\left(\tau_{e q}, y\right)$. This in turn yields the condition:

$$
E_{y}\left(\max \left\{V_{p}\left(\tau^{*}, d_{L}, y\right), V_{d}\left(\tau^{*}, y\right)\right\}-V_{d}\left(\tau_{e q}, y\right)\right)>0
$$

So an arbitrarily large $b_{H}$ does not make the option of choosing $\tau_{e q}$ arbitrarily bad because the debtor can always opt to default on its debt. Hence incentives for the ex-ante optimal fiscal adjustment can be provided as long as there is a large set of states where the difference between honoring its debt and defaulting is large. The bottom line is that it is easier to provide incentives for fiscal adjustment when the debtor's situation in not too bad.

Last, note that transfers have a greater effect when the $g \geq 0$ constraint binds. If the government budget constraint is not binding, $\partial V_{p} / \partial T=1$ : a transfer of resources $\Delta T$ leads to an increase in $g$ by $\Delta T$ and the marginal utility of this higher public spending is one because of the linearity assumption. However, when the $g \geq 0$ constraint binds, the transfer $\Delta T$ is used not to increase $g$, but to reduce $b$ and relax the binding constraint. An extra gain arises because a reduction in $b$ leads to a reduction in the odds of default and, consequently, an increase in the price of debt $q$ (this result is presented in Appendix A.6). The implication is that transferring resources to the debtor when they will be used to repay maturing debt provides more incentives to the debtor for each dollar it receives.

\section{The IMF as a commitment device for fiscal ajustment}

Overcoming the time inconsistency problem discussed above through private contracting is problematic because of the transactions costs involved. The level of fiscal adjustment 
has to be chosen and then verified, which in reality requires a non-trivial amount of effort. Individual creditors would have incentives to free ride on others' monitoring efforts. But a bigger long-term player concerned with social welfare and able to commit to transfer resources to the debtor after observing the implementation of some level of fiscal policy could overcome this problem.

We think of the IMF and the EU as institutions able to carry out this type of implicit contract. An institution like the IMF, for instance, can send a mission to a country, determine what the optimal $\tau$ should be and, after verifying the implementation of the "contracted", $\tau$ lend money to the debtor at below market rates (which is equivalent to transfering resources).

The arrangement works like this: having observed $\tau^{\prime}=\tau^{*}$, the IMF lends to the troubled country at below market rates and attaches seniority clauses to its lending, implying that creditors that had previously lent to that country become juniors. So we need to show that this arrangement works in a similar way to the implicit private contract above for debtor and lenders, and that the IMF breaks even in the end.

From the debtors' point of view, debt to be repaid is $d_{H}$. If $\tau=\tau^{*}$ is implemented, however, the IMF commits to lend money at subsidized rates, which is equivalent to a reduction in the level of debt (from $d_{H}$ to $d_{L}$ ). Since a dollar is mostly valuable for the debtor when the constraint is binding, such financial aid would preferably be concentrated in situations where $g=0$. As long as the condition in (11) holds, the debtor will find it optimal to indeed follow IMF's directives and will achieve the first-best.

In case of default, official and private lenders would eventually receive some payments because when the debtor regains access to markets, lenders are entitled to a proportion $\nu$ of their previously contracted debt. Seniority implies that the IMF will then be repaid in full, and other lenders will be entitled to whatever is left after the IMF has been paid. Hence, IMF lending is virtually risk free. ${ }^{15}$

From the lenders' point of view, if the debtor chooses $\tau=\tau^{*}$, they become juniors to the IMF, which means they transfer to the IMF rights to some of the debt that will eventually be recovered in case of default. If the debtor repays, lenders' assets are $d_{H}$; otherwise they are due a lower fraction of the recovered debt. For a risk-neutral lender, in expected terms this is equivalent to a reduction in the level of debt (from $d_{H}$ to $d_{L}$ ).

Therefore, at the end of the day, the IMF receives risk-free interest rates payments in expected terms, private creditors break-even, and the debtor country ends up implement-

\footnotetext{
${ }^{15}$ This reasoning requires a large enough recovered value of debt $\nu$ in order to cover all IMF's lending. Hence the amount of incentives for fiscal adjustment is also constrained by $\nu$.
} 
ing a larger tax rate. Social welfare thus improves. In our view, this kind of agreement strongly resembles some of the real world deals we observe, including IMF programmes and the recent deals struck in the Eurozone. We now turn to these.

\subsection{IMF adjustment programmes}

There is a heated debate about the role the IMF should play and how it ought operate. ${ }^{16}$ The usual role attributed to the IMF is the provision of loans to countries facing liquidity problems. ${ }^{17}$ By lending money to countries in trouble, the IMF would allow them time to pursue beneficial economic reforms or help them to catalyze private funds. ${ }^{18}$ Furthermore, IMF programs can also assist domestic leaders in overcoming internal political barriers to reforms, or even signal its type to financial markets in a setting of imperfect information. ${ }^{19}$

There is also a related debate about IMF conditionalities. Dreher (2009) presents several possible rationales for them: (i) a way to transfer resources to creditors in detriment of debtor's welfare; (ii) a mechanism through which countries can "signal their type" to markets; (iii) a way for domestic leaders to implement politically difficult but beneficial policies that face the opposition of some well-organized groups inside the country; (iv) the perhaps only way benevolent international actors have to impose "good policies" on poorly informed domestic policymakers; and (v) as commitment devices for investing rather than consuming (Sachs (1989)) or for undertaking policies that increase the costs of default (Fafchamps (1997)).

Here, conditionality improves welfare in debtor countries for solving a time-inconsistency problem that renders taxes too low and default too frequent. IMF loans at below market rates are provided in exchange for a tougher fiscal policy. That scales down the amount of debt required to satisfy the government's binding budget constraint. This tougher fiscal stance is closer to the debtor's first-best under commitment, but diverges from the debtor country's preferred ex-post policy.

According to the model, it is wrong to evaluate the desirability of IMF programs based solely on a comparison between the time-consistent fiscal policy and what the IMF imposes on the country, not only because IMF conditionalities come attached with expected

\footnotetext{
${ }^{16}$ Bird (2007) provides a comprehensive survey.

${ }^{17}$ The IMF's Articles of Agreement state that one of the IMF's purposes is to provide confidence to members by making the general resources of the Fund temporarily available to them under adequate safeguards, thus providing them with opportunity to correct maladjustments in their balance of payments without resorting to measures destructive of national or international prosperity.

${ }^{18}$ Se Corsetti, Guimaraes and Roubini (2006) for a model of IMF's catalytic finance.

${ }^{19}$ See Drazen (2002) for a more positive view and Vreeland (2003) for a more negative view on IMF programmes in presence of heterogeneous agents and political issues.
} 
financial support but also because the time-consistent fiscal policy is itself suboptimal. The IMF is often criticized for imposing excessively tough measures on debtor countries. Summarizing this view, Dreher (2009) states that "if the Fund and the governments disagree about appropriate policies, it is the government that should have the final say, and not the Fund". That is not true in the model because the debtor is time inconsistent.

The model is also related to a policy discussion about the IMF's status as a senior lender. ${ }^{20}$ Here IMF seniority plays the role of a transfer from creditors to the IMF but that is part of an optimal deal linking the IMF, creditors and the debtor country. Transfers from creditors to the debtor (through the IMF or not) provide a way to implement the optimal fiscal adjustment.

The analysis in this paper is restricted to fiscal policy. As Dreher (2009) and Bird (2007) point out, IMF conditionality has often included a wide set of policies, about which this paper has nothing to say. Moreover, there is also a debate about whether IMF adjustment programmes effectively affect policies (see Easterly (2005) and the discussion in Dreher (2009)), and again, we have nothing to add to that discussion.

\subsection{The European sovereign debt crisis}

The unfolding of events in Europe during 2010/2012 period resembles the analysis in this paper. Crisis resolution there looks like the implementation of an implicit contract similar to the one we propose here. Since the crisis erupted, leaders of major debtor and creditor countries have been often meeting to discuss fiscal consolidation plans and assistant loan packages, first through the ESFM and more recently via the ESM.

Financial aid has been granted. Some countries in Europe (most notably Greece) have been treading on the verge of debt default in the last couple of years. In 2010, unable to cope with its debt obligations, Greece was granted more than 100 billion euros in bridge loans by the IMF and the EU at subsidized rates (lower than market rates for greek debt). These loans later proved insufficient to calm investors and in December 2011, as part of a broader plan to avert a break-up of the Eurozone, European leaders agreed on another bail-out totalling 130 billion euros. In 2012, another package came along. Greece is not an isolated case, since subsidized loans were also extended to Ireland, Portugal and to Spanish banks.

Tough fiscal measures have been undertaken. Indirect evidence - like a series of popular unrest following each new austerity package - supports the idea that fiscal policy became

\footnotetext{
${ }^{20}$ The trade-off involved is studied by Saravia (2010): senior lending allows the IMF to provide more liquidity, but the possibility of large senior lending in the future might reduce ex-ante incentives for private lending.
} 
"tight" in Greece and elsewhere. ${ }^{21}$ This is consistent with an interpretation of fiscal policy that is too tough ex-post (but perhaps not ex-ante). In return, though, official money from the ECB, Europe and IMF flowed in at below market rates to avert a costly default.

The policies pursued by Italy's government following Berlusconi's fall and also by Spain's government are another example of the mechanism discussed here. By submitting to the EU and ECB 's demand for fiscal austerity these countries were granted money from the ECB, directly through secondary market purchases of their bonds and indirectly through the LTRO facility that provided enormous amount of liquidity to banks at low rates (and banks in the Euro area did follow president Sarkozy suggestion of using these cheap funds to buy high-yielding sovereign bonds, an operation dubbed "Sarko Trade" in financial markets).

Interestingly, this extra help from ECB came after peripheral Europe agreed to implement austere fiscal policies. The ECB's president, Mario Draghi, made clear to countries' leaders that fiscal adjustment should come first. In his words: "What I believe our economic and monetary union needs is a new fiscal compact - a fundamental restatement of the fiscal rules together with the mutual fiscal commitments that euro area governments have made. Other elements might follow, but the sequencing matters." ${ }^{22}$

\section{Final remarks}

There is a fast growing academic literature following the footsteps of Eaton and Gersovitz (1981) that provides insights to some important questions about sovereign debt and default. However, most of this literature cannot address some of the main policy debates surrounding the European debt crisis for having no role for fiscal adjustment in the model. This paper studies incentives for fiscal adjustment in an otherwise standard model of sovereign default. Inefficiently low fiscal adjustment - a problem related to some of the main current policy issues - arises as a result of imperfect commitment to repay sovereign debt - a usual assumption in the academic literature on sovereign risk. Hence one contribution of this paper is to bring a well-established academic literature closer to policy discussions.

The vast majority of dynamic models in the recent literature on sovereign debt and default are solved quantitatively. That is not surprising given the difficulties in obtained closed form results in this literature. In our view, however, analytical results provide insightful results, even if that requires adding a few simplifying assumptions to the models.

\footnotetext{
${ }^{21}$ Quoting Barry Eichengreen, "the crisis countries have, in fact, shown remarkable resolve in implementing painful cuts" (http://www.project-syndicate.org/commentary/eichengreen25/English)

${ }^{22}$ http://www.ecb.int/press/key/date/2011/html/sp111201.en.html
} 
Ultimately, we see both approaches as complements and quantitative versions of this model could provide more insight on the incentives for fiscal adjustment for a debtor government under the risk of default.

\section{References}

[1] Aguiar, Mark and Gopinath, Gita, 2006, "Defaultable debt, interest rates and the current account", Journal of International Economics 69, 64-83.

[2] Alfaro, Laura and Kanczuk, Fabio, 2005, "Sovereign debt as a contingent claim: a quantitative approach", Journal of International Economics 65, 297-314.

[3] Arellano, Cristina, 2008, "Default risk and income fluctuations in emerging economies", American Economic Review 98, 690-712.

[4] Bird, Graham, 2007, "The IMF: a bird's eye view of its role and operations", Journal of Economic Surveys 21, 683-745.

[5] Broner, Fernando and Ventura, Jaume, 2011, "Globalization and Risk Sharing", Review of Economic Studies 78, 49-82.

[6] Brutti, Filippo, 2011, "Sovereign Defaults and Liquidity Crises", Journal of International Economics 84, 65-72.

[7] Corsetti, Giancarlo; Guimaraes, Bernardo and Roubini, Nouriel, 2006, "International lending of last resort and moral hazard: A model of IMF's catalytic finance", Journal of Monetary Economics 53, 441-471

[8] Cuadra, Gabriel; Sanchez, Juan M. and Sapriza, Horacio, 2010, "Fiscal policy and default risk in emerging markets", Review of Economic Dynamics 13, 452-469.

[9] Cuadra, Gabriel and Sapriza, Horacio, 2008, "Sovereign default, interest rates and political uncertainty in emerging markets", Journal of International Economics 76, $78-88$.

[10] Drazen, Allan, 2002, "Conditionality and ownership in IMF lending: a political economy approach", IMF Staff Papers 49, 36-67.

[11] Dreher, Axel, 2009, "IMF conditionality: theory and evidence", Public Choice 141, 233-267. 
[12] Easterly, William, 2005, "What did structural adjustment adjust?: The association of policies and growth with repeated IMF and World Bank adjustment loans", Journal of Development Economics 76, 1-22.

[13] Eaton, Jonathan and Gersovitz, Mark, 1981, "Debt with potential repudiation: theoretical and empirical analysis", Review of Economic Studies 48, 289-309.

[14] English, William, 1996, "Understanding the costs of sovereign default: American state debts in the 1840's", American Economic Review 86, 259-275.

[15] Fafchamps, Marcel, 1997, "Sovereign debt, structural adjustment, and conditionality", Journal of Development Economics 50, 313-335.

[16] Fuentes, Miguel and Saravia, Diego, 2010, "Sovereign defaulters: Do international capital markets punish them?", Journal of Development Economics 91, 336-347.

[17] Guimaraes, Bernardo, 2011, "Sovereign default: which shocks matter?", Review of Economic Dynamics 14, 553-576.

[18] Hatchondo, Juan C.; Martinez, Leonardo and Sosa-Padilla, Cesar, 2012, "Debt dilution and sovereign default risk", working paper.

[19] Martinez, Jose V. and Sandleris, Guido, 2011, "Is it punishment? Sovereign defaults and the decline in trade", Journal of International Money and Finance 30, 909-930.

[20] Mendoza, Enrique and Yue, Vivian, 2012, "A general equilibrium model of sovereign default and business cycles", Quarterly Journal of Economics 2012, 889-946.

[21] Panizza, Ugo; Sturzenegger, Federico and Zettelmeyer, Jeromin, 2009, "The Economics and Law of Sovereign Debt and Default", Journal of Economic Literature 47, $651-98$.

[22] Pouzo, Demian, 2010, "Optimal Taxation with Endogenous Default under Incomplete Markets", mimeo.

[23] Rose, Andrew, 2005, "One reason countries pay their debts: renegotiation and international trade", Journal of Development Economics 77, 189-206.

[24] Sachs, Jeffrey, 1989, "Conditionality, Debt Relief, and the Developing Country Debt Crisis", in Developing Country Debt and Economic Performance Volume 1: The International Financial System, 255-296, Ed: Jeffrey Sachs. 
[25] Saravia, Diego, 2010, "On the role and effects of IMF seniority", Journal of International Money and Finance 29, 1024-1044.

[26] Sturzenegger, Federico and Zettelmeyer, Jeromin, 2008, "Haircuts: Estimating investor losses in sovereign debt restructurings, 1998-2005", Journal of International Money and Finance 27, 780-805.

[27] Tomz, Michael, 2007, "Reputation and international cooperation", Princeton University Press.

[28] Tomz, Michael and Wright, Mark, 2007, "Do countries default in 'bad times'?", Journal of the European Economic Association 5, 352-60.

[29] Vreeland, James, 2003, "The IMF and Economic Development", Cambridge University Press.

[30] Yue, Vivian, 2010, "Sovereign default and debt renegotiation", Journal of International Economics 80, 176-187.

\section{A Appendix}

\section{A.1 First-best with contingent taxation}

Now we charactarize the first-best allocation in which the debtor country has access to contingent taxes - that is, it can set the tax rate upon observing the realization of output and can issue contingent debt. With this structure a costly default never occurs because repayment can be agreed to be zero in some states of nature. Given that $\beta\left(1+r^{*}\right)<1$ and the utility is linear in the consumption of the public good, a benevolent government should set $g_{i}=0$ for all $i>1$. Taking this into account, it solves the following problem:

$$
u\left(c_{1}\right)+g_{1}+\sum_{t=2}^{\infty} \beta^{t-1} u\left(c_{t}\right)
$$

Subject to:

$$
\sum_{t=1}^{\infty} \frac{c_{t}}{\left(1+r^{*}\right)^{t-1}}+g_{1}=\sum_{t=1}^{\infty} \frac{y_{t}}{\left(1+r^{*}\right)^{t-1}}
$$

Given the assumption $u^{\prime}\left(y_{1}\right)<1$, and the Inada condition, $u^{\prime}\left(c_{1}\right)=1$. The intertemporal FOC in turn is $1=\left(\beta\left(1+r^{*}\right)\right)^{i-1} E\left(u^{\prime}\left(c_{i}\right)\right)$ for $i \geq 2$. Since $\beta\left(1+r^{*}\right)<1, u^{\prime}\left(c_{t+1}\right)>u^{\prime}\left(c_{t}\right)$ for all $t$, meaning private consumption falls over time (but concavity prevents it from being zero for all $t \geqslant 2$ ). 


\section{A.2 Lemma 5}

Lemma 5 For given $\tau$ and $y$, there exists $\bar{d}>0$ such that there is default in the current period if and only if $d^{\prime}>\bar{d}$.

Proof. The value function in case of default is not affected by $d$. In case of repayment, an increase in $d$ reduces $g$ by the same amount if the government budget constraint is not binding and is at least as bad if the constraint is binding. Hence:

$$
\begin{aligned}
& \frac{\partial V_{d}}{\partial d^{\prime}}=0 \\
& \frac{\partial V_{p}}{\partial d^{\prime}} \leq-1
\end{aligned}
$$

If $d^{\prime}=0, V_{p}>V_{d}$ for all $y$ and $\tau$ because all possible $g$ under default are also possible under repayment (repayment includes the set of options available in case of default) and defaulting leads to a direct utility loss. For high enough d, consumption conditional on repayment approaches 0 , hence the marginal utility of consumption and, consequently, $V_{p}$ can be arbitrarily low, so $V_{p}<V_{d}$. Combining all those statements yields the claim.

\section{A.3 Proof of proposition 1}

Taking derivatives of the value functions, and applying the envelope theorem with respect to $d^{\prime}$ and $\tau^{\prime}$ yields the derivatives. That shows that the difference between value functions $V_{p}$ and $V_{d}$ is not affected by $y$. Since there are no other shocks in the model, agents know in advance whether debt will be honoured or not. Since the price of debt falls to 0 if debt will not be repaid, and it is never optimal for a country to sell bonds at zero price, default never occurs.

\section{A.4 Proof of proposition 2}

Proof of the first statement

First, we show that when the constraint $g \geq 0$ is locally binding,

$$
\frac{d V_{p}}{d y}>u^{\prime}(y(1-\tau))(1-\tau)+\tau
$$

Since the constraint on $g$ is binding,

$$
V_{p}(\tau, d, y)=\max _{b, \tau^{\prime}}\left\{u(y(1-\tau))+\beta E\left[V\left(\tau^{\prime},(1-\phi) d+b, y^{\prime}\right)\right]\right\} \text {, with } q b=\phi d-\tau y
$$

thus

$$
\frac{\partial V_{p}}{\partial y}=u^{\prime}(y(1-\tau))(1-\tau)+\left.\beta \frac{\partial E\left[V\left(\tau^{\prime},(1-\phi) d+b, y^{\prime}\right)\right]}{\partial b} \frac{\partial b}{\partial y}\right|_{b=(\phi d-\tau y) / q}
$$

We need show that the second term is larger than $\tau$. Note that

$$
\left.\frac{\partial(q b)}{\partial y}\right|_{b=(\phi d-\tau y) / q}=\left.\frac{\partial(q b)}{\partial b} \frac{\partial b}{\partial y}\right|_{b=(\phi d-\tau y) / q}
$$


and since

$$
\left.\frac{\partial(q b)}{\partial y}\right|_{b=(\phi d-\tau y) / q}=-\tau \quad \text { and } \quad \frac{\partial(q b)}{\partial b}=q(1-\epsilon)
$$

we have

$$
\left.\frac{\partial b}{\partial y}\right|_{b=(\phi d-\tau y) / q}=-\frac{\tau}{q(1-\epsilon)}
$$

Moreover, since the constraint is locally binding, the derivative of the value function with respect to $b$ is negative (the country would prefer a slightly negative $g$ than $g=0$ ). Therefore

$$
q(1-\epsilon)<-\beta \frac{\partial E\left[V\left(\tau^{\prime},(1-\phi) d+b, y^{\prime}\right)\right]}{\partial b}
$$

Combining (14) and (15) yields:

$$
\left.\beta \frac{\partial E\left[V\left(\tau^{\prime},(1-\phi) d+b, y^{\prime}\right)\right]}{\partial b} \frac{\partial b}{\partial y}\right|_{b=(\phi d-\tau y) / q}>\tau
$$

Using (13), that implies the condition in (12).

When $g>0, d V_{p}(\tau, d, y) / d y$ is as given by (1). Moreover, $d V_{d}(\tau, d, y) / d y$ is always given by (1). Hence

$$
\frac{d V_{p}}{d y} \geq \frac{d V_{d}}{d y}
$$

There cannot be default for all $y$ since that implies $q=0$ in the previous period, which is never optimal.

Suppose there is default for some $y_{1} \in\left(y_{L}, y_{H}\right)$, which implies $V_{d}\left(\tau, d, y_{1}\right)>V_{p}\left(\tau, d, y_{1}\right)$. Since there cannot be default for all $y$, there exists $y_{2}$ such that $V_{d}\left(\tau, d, y_{2}\right) \leq V_{p}\left(\tau, d, y_{2}\right)$. Define $\tilde{y}$ as the smallest value of $y$ such that $V_{d}(\tau, d, y) \leq V_{p}(\tau, d, y)$ - which exists because the value functions are continuous in $y$. Then there is default for all $y<\tilde{y}$.

Last, no default for $y=\tilde{y}$ implies no default for all $y>\tilde{y}$, because owing to $(16), V_{p}(\tau, d, \tilde{y}) \geq$ $V_{d}(\tau, d, \tilde{y})$ implies $V_{p}(\tau, d, y) \geq V_{d}(\tau, d, y)$ for all $y>\tilde{y}$.

Proof of the second statement

When the constraint $g \geq 0$ is slack,

$$
\frac{d V_{p}}{d y}=\frac{d V_{d}}{d y}=u^{\prime}(y(1-\tau))(-y)+y
$$

If the constraint on $g$ is binding,

$$
\frac{\partial V_{p}}{\partial \tau}=u^{\prime}(y(1-\tau))(-y)+\left.\beta \frac{\partial E\left[V\left(\tau^{\prime},(1-\phi) d+b, y^{\prime}\right)\right]}{\partial b} \frac{\partial b}{\partial \tau}\right|_{b=(\phi d-\tau y) / q}
$$

First we show that

$$
\left.\beta \frac{\partial E\left[V\left(\tau^{\prime},(1-\phi) d+b, y^{\prime}\right)\right]}{\partial b} \frac{\partial b}{\partial \tau}\right|_{b=(\phi d-\tau y) / q}>y
$$


Repeating the steps of the proof of proposition 2 that lead to equation (14), we have

$$
\left.\frac{\partial b}{\partial \tau}\right|_{b=(\phi d-\tau y) / q}=-\frac{y}{q(1-\epsilon)}
$$

and using (15) we obtain the expression in (17).

An argument similar to that in proposition 2 establishes the second statement.

\section{Proof of the second statement}

If the probability of default next period is strictly positive, at the smallest value $y$ such that the debtor is indifferent between defaulting or not (call it $\left.\tilde{y}(\tau, d) \in\left(y_{L}, y_{H}\right)\right)$ the value function $V_{p}$ crosses $V_{d}$, so

$$
\left.\frac{d V_{p}(\tau, d, y)}{d y}\right|_{y=\tilde{y}(\tau, d)}>\left.\frac{d V_{d}(\tau, d, y)}{d y}\right|_{y=\tilde{y}(\tau, d)}=u^{\prime}(y(1-\tau))(1-\tau)+\tau
$$

which can only be true if (15) holds and implies the constraint on $g$ is binding. But that implies the expression in (17) which leads to

$$
\left.\frac{d V_{p}(\tau, d, y)}{d \tau}\right|_{y=\tilde{y}(\tau, d)}>\left.\frac{d V_{d}(\tau, d, y)}{d \tau}\right|_{y=\tilde{y}(\tau, d)}
$$

so an increase in $\tau$ makes $V_{p}(\tau, d, \tilde{y}(\tau, d))$ strictly larger than $V_{d}(\tau, d, \tilde{y}(\tau, d))$. Using the results in the first statement of this proposition, the smallest value of $y$ such that the debtor is now indifferent between repaying and defaulting is smaller than $\tilde{y}(\tau, d)$. Since the distribution of $y$ has full support in $\left[y_{L}, y_{H}\right]$, the probability of default next period becomes smaller when $\tau^{\prime}$ increases.

\section{A.5 Proof of proposition 3}

If the price of debt is conditional on $\tau^{\prime}$, then using (1) we get

$$
\frac{\partial q}{\partial \tau^{\prime}}=\frac{\partial \pi_{1}}{\partial \tau^{\prime}} \frac{1}{\left(1+r^{*}\right)}\left(\phi-v q\left(v d^{\prime}\right) \frac{\zeta}{\left(\zeta+r^{*}\right)}+(1-\phi) q\left(d^{\prime \prime}\right)\right)+\frac{\pi_{1}}{\left(1+r^{*}\right)}(1-\phi) \frac{\partial q\left(d^{\prime \prime}\right)}{\partial \tau^{\prime}}
$$

The third statement of Proposition 2 establishes that the probability that debt will be repaid next period is increasing in $\tau^{\prime}\left(\partial \pi_{1} / \partial \tau^{\prime}>0\right)$ as long as there is a positive probability of default and the term in brackets is positive owing to the assumption $\phi>\nu$, since $q\left(v d^{\prime}\right) \leq 1$ and $\zeta /\left(\zeta+r^{*}\right) \leq 1$. Hence the first term in the expression for $\partial q / \partial \tau^{\prime}$ is positive.

A higher $\tau^{\prime}$ increases the expected revenues for the following period, so it might relax the budget constraint. In case the debtor chooses to default in the following period, $q\left(d^{\prime \prime}\right)$ is not affected. If the debtor does not default, higher revenues will mean either (i) a lower $d^{\prime \prime}$ in case the constraint $g \geq 0$ is binding so that a larger $\tau^{\prime}$ allows for a lower $b^{\prime}$, or (ii) the same $d^{\prime \prime}$ in case the constraint $g \geq 0$ was not binding. In either case $\partial q\left(d^{\prime \prime}\right) / \partial \tau^{\prime} \geq 0$. 


\section{A.6 Transfers when the debtor is constrained}

Suppose the debtor is constrained and receives transfer $T$, so that $\tau y+T+q b-\phi d=0$. Then

$$
b=\frac{\phi d-\tau y-T}{q}
$$

Now

$$
\left.\frac{\partial(q b)}{\partial T}\right|_{b=(\phi d-T-\tau y) / q}=\left.\frac{\partial(q b)}{\partial b} \frac{\partial b}{\partial T}\right|_{b=(\phi d-T-\tau y) / q}
$$

and since

$$
\left.\frac{\partial(q b)}{\partial T}\right|_{b=(\phi d-T-\tau y) / q}=-1 \quad \text { and } \quad \frac{\partial(q b)}{\partial b}=q(1-\epsilon)
$$

we get

$$
\left.\frac{\partial b}{\partial T}\right|_{b=(\phi d-T-\tau y) / q}=-\frac{1}{q(1-\epsilon)}
$$

Moreover

$$
\frac{\partial V_{p}(\tau, d, y)}{\partial T}=\left.\beta \frac{\partial E\left[V\left(\tau^{\prime}, d^{\prime}, y^{\prime}\right)\right]}{\partial b} \frac{\partial b}{\partial T}\right|_{b=(\phi d-T-\tau y) / q}
$$

If the constraint is binding, (15) holds. Combining it with (18) and (19) yields:

$$
\frac{\partial V_{p}(\tau, d, y)}{\partial T}>1
$$

